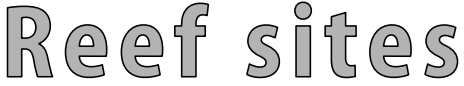

\section{First record of the basslet Gramma dejongi outside of Cuba}

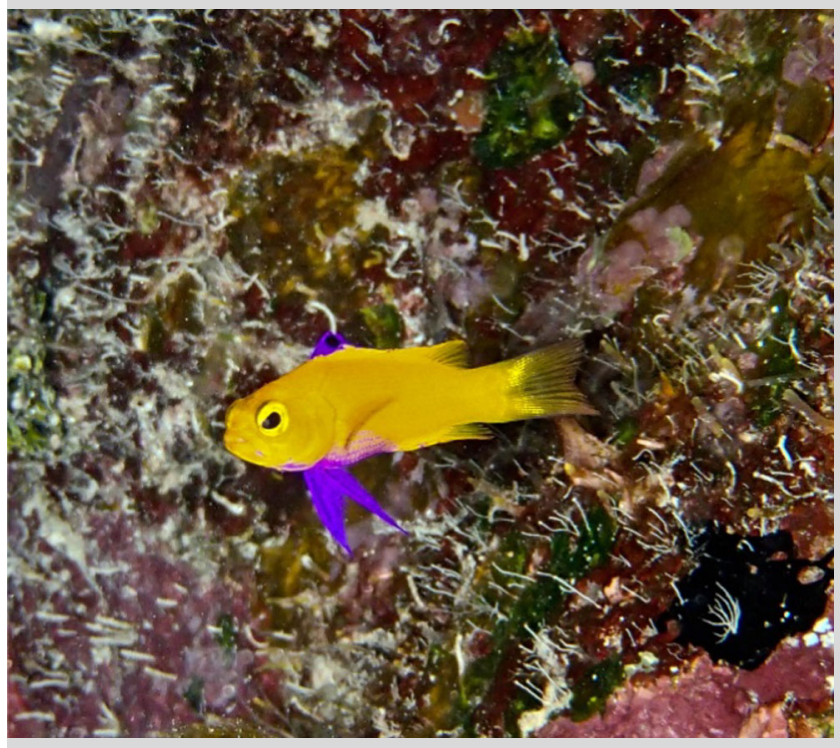

Fig. 1 Gramma dejongi individual at Little Cayman

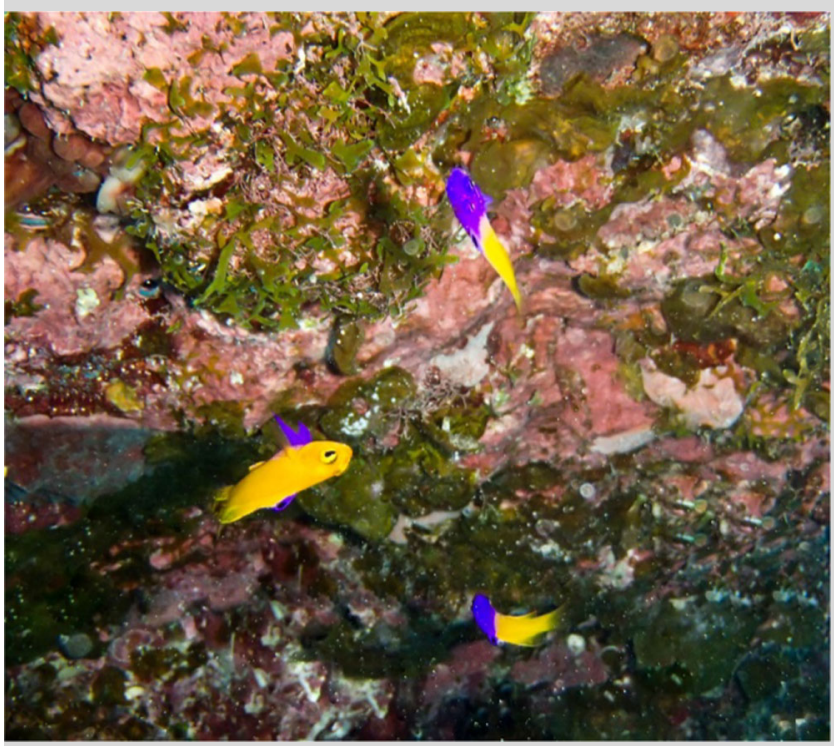

Fig. 2 Gramma dejongi individual among several G. loreto individuals at Little Cayman
The basslet Gramma dejongi, a recently discovered sibling species to the fairy basslet ( $G$. loreto), was regarded as endemic to Cuba (Victor and Randall 2010). Here we report the first documented sightings of $G$. dejongi at Little Cayman Island. The Cayman Islands are located on an oceanic ridge that extends southwest from the Sierra Maestra Mountains in southeastern Cuba. Situated approximately $220 \mathrm{~km}$ due south of Cuba, Little Cayman and Cayman Brac are the closest islands to the town of Trinidad, where G. dejongi was first reported (Victor and Randall 2010). A single G. dejongi individual (Fig. 1) was first sighted in July 2013 among a group of G. loreto (Fig. 2) and was visually identified by comparing its morphology and coloration to those described by Victor and Randall (2010).

The Little Cayman specimen was $60 \mathrm{~mm}$ in total length, exceeding the maximum size reported for the species (i.e., $45 \mathrm{~mm}$, Victor and Randall 2010). The individual was found at $18 \mathrm{~m}$ on a spur-and-groove formation $1.5 \mathrm{~km}$ east of the Bloody Bay Marine Park. We located the same $G$. dejongi individual in August 2013 at the exact site where it was first observed, suggesting the species is highly site-attached. Like G. loreto, the Little Cayman $G$. dejongi specimen was repeatedly observed upside down. Our observations indicate that second-hand reports of smaller size and vertical-swimming behavior in the original description of $G$. dejongi may not be diagnostic (Victor and Randall 2010).

The discovery of a single $G$. dejongi individual in the Cayman Islands does not imply that large-scale recruitment of the species has occurred in the area. However, sighting $G$. dejongi outside of Cuba does suggest that the species is capable of dispersing pelagically to nearby islands.

Acknowledgments The authors would like to thank S. Bejarano for her insightful comments.

\section{References}

Victor BC, Randall JE (2010) Gramma dejongi, a new basslet (Perciformes: Grammatidae) from Cuba, a sympatric sibling species of $G$. loreto. Zool Stud 49(6):865-871

\section{K. E. Lohr ( $\square)$ · E. F. Camp · C. Manfrino}

Central Caribbean Marine Institute, Little Cayman Research Centre, Little Cayman KY3-2501, Cayman Islands

e-mail: katielohr@reefresearch.org

E. F. Camp

Coral Reef Research Unit, University of Essex, Colchester, Essex CO4 3SQ, England, UK

C. Manfrino

Kean University, Union, NJ 07083, USA

Received: 30 August 2013/Accepted: 26 September 2013/Published online: 7 November 2013

Coral Reefs (2014) 33:221

(C) Springer-Verlag Berlin Heidelberg 2013 DOI 10.1007/s00338-013-1089-y 